\title{
Role of Acid-Base Balance at Admission in Risk Stratification of Patients with Acute Myocardial Infarction
}

\author{
Abdel Mohsen Mostafa Abou Alia, AbdelRahmanI brahim, Akram Ibrahim Younis
}

\begin{abstract}
:
Background: Few data are available on the acid-base imbalance in acute myocardial infarction (AMI).

Aim of the work: $i$ s to evaluate the role of acid-base balance on the in-hospital complications of AMI patients submitted to coronary revascularization.

Patients and methods: 100 patients with ST elevation AMI. All patients were subjected at admission to full history taking including risk factors of coronary artery disease, electrocardiogram, echocardiogram, laboratory analysis and basic metabolic profile, and during ICU Stay to continuous monitoring to detect occurrence of arrhythmias and signs or symptoms of heart failure $(H F)$.
\end{abstract}

Results: smoking, hypertension, diabetes and family history for coronary artery disease (FH) were predictors for the occurrence of arrhythmia, while, dyslipidemia, age and male gender were not predictors. In this study; hypertension, dyslipidemia, male gender and FH were predictors for the occurrence of reduced ejection fraction $(E F)$, while smoking, diabetes and age were not predictors. In this study; pH<7.35, serum HCO3 <22, base deficit $>-3$, anion gap $>12$, serum $\mathrm{Cl} / \mathrm{Na}<0.79$, and high uric acid level were predictors for the occurrence of arrhythmia and reduced EF. There was a positive correlation between EF and $\mathrm{pH}$, serum bicarbonate level, base excess, and serum chloride/sodium ratio. While there was a negative correlation between EF and anion gap and serum uric acid level.

Conclusion: PH, serum bicarbonate level, base excess, serum chloride/sodium ratio and anion gap are predictors for the occurrence of arrhythmia and reduced EF.

\section{INTRODUCTION}

Few data are available on the acid-base imbalance in acute myocardial infarction (AMI) submitted to coronary revascularization, and earlier studies on this topic differ with respect to patients' selection criteria, treatment and evaluated parameters. Anion gap acidosis on admission is a powerful predictor of short-term mortality, independent of other biochemical, historical and electrocardiographic data available at the time of admission (Valente et al., 2009).

Acidosis has long been thought to depress cardiac performance and reduce myocardial responsiveness to catecholamines (Schotola et al., 2012).

The measurement of anion gap at the time of presentation with AMI may improve initial risk stratification and the early targeting of aggressive interventions.

\section{AIM OF THE WORK}

The aim of this work is to evaluate the role of acid-base balance on the in-hospital complications of acute myocardial infarction patients submitted to coronary revascularization.

\section{Patients AND Methods}

\subsection{Study Patients}

This study was carried out on 100 patients with acute myocardial infarction from those attending the coronary care units at the national heart institute between May 2014 and November 2014. These patients were diagnosed by history of chest pain, electrocardiogram, echocardiogram, and serum cardiac enzymes levels. 


\subsection{Exclusion Criteria}

Patients were excluded from this study if:

- Previous uncontrolled arrhythmia proved by history or ECG.

- EF less than $45 \%$ in previous echocardiogram.

\subsection{Methods}

After informed consent all patients were subjected to:

At admission: full history taking including risk factors of coronary artery disease, electrocardiogram, echocardiogram, laboratory analysis and basic metabolic profile.

During ICCU Stay: continuous monitoring to detect occurrence of arrhythmias and signs or symptoms of HF as dyspnea, orthopnea, paroxysmal nocturnal dyspnea, auscultation of fine baseal crepitation and lower limb edema.

1- Electrocardiogram: to detect ST segment elevation or depression, T-wave inversion or new left bundle branch block, and also to detect presence of arrhythmia. The diagnosis as follow:

- STEMI and NSTEMI were diagnosed according to Thygesen et al., 2012.

- Frequent ECG and continuous 24 hours monitoring to detect and record arrhythmias, especially ventricular arrhythmias as ventricular ectopics, ventricular tachycardia and ventricular fibrillation.

2- Echocardiogram: to measure the EF using the biplane method of disks (modified Simpson method) as recommended by the American Society of Echocardiography(Lang et al., 2005). In this EF $\leq$ $45 \%$ was considered impaired.

3- Laboratory Analysis:

- Serum cardiac biomarkers level: cardiac troponin (cTn) T was measured in all patients using value exceeding the 99th percentile upper limits of normal. Patients with negative cardiac troponin within 6 hours of the onset of symptoms that were consistent with STEMI or NSTEMI, cardiac troponin was repeated after another 6 hours.

- Arterial blood gases analysis to measure $\mathrm{pH}, \mathrm{HCO}_{3}$ and base excess. Acidosis was considered if $\mathrm{pH}<7.35, \mathrm{HCO}_{3}<22 \mathrm{mmol} / \mathrm{l}$ or base excess was $>-3 \mathrm{mmol} / \mathrm{l}$.

- Measurement of serum electrolytes level, especially sodium and chloride levels, then anion gap was calculated as follows:

$\mathrm{AG}=\mathrm{Na}^{+}-\left(\mathrm{Cl}^{-}+\mathrm{HCO}_{3}\right)$

Acidosis was considered if AG > $12 \mathrm{mmol} / \mathrm{l}$ (Morris and Low, 2008).

- Chloride/sodium ratio was calculated and was used as an indicator of acidosis if this ratio was < 0.79 (Durward et al., 2001).

- Serum creatinine level measurement in order to calculate the estimated glomerular filtration rate using the modification of diet in renal disease equation, abbreviated MDRD equation as follow:

$\operatorname{GFR}\left(\mathrm{ml} / \mathrm{min} / 1.73 \mathrm{~m}^{2}\right)=175 \times \operatorname{SerumCr}^{-1.154} \times \operatorname{age}^{-0.203} \times 1.212$ (if patient is black) $\times 0.742$ (if female)

Data from this equation were interpreted as normal if GFR $\geq 90 \mathrm{~mL} / \mathrm{min} / 1.73 \mathrm{~m}^{2}$ (Levey et al.,2009).

- Serum uric acid measurement to assess its role in early complications of acute myocardial infarction. Patients of this study were divided into three groups according to serum uric acid level, $<3 \mathrm{mg} / \mathrm{dl}, 3-5 \mathrm{mg} / \mathrm{dl}$ and $>5 \mathrm{mg} / \mathrm{dl}$.

4- Statistical Analysis:

Data were analyzed using IBM@ SPSS $\odot$ Statistics version 22 (IBM $\odot$ Corp., Armonk, NY, USA) and MedCalc $($ ) version 13 (MedCalc $\odot$ Software bvba, Ostend, Belgium). The D'Agostino-Pearson test was used to examine the normality of numerical data distribution. Normally distributed numerical variables were presented as mean and standard deviation (SD), and intergroup differences were compared using the unpaired t test (for comparison of two groups) or the one-way analysis of variance 
(ANOVA) (for comparison of multiple groups). The Student-Newman-Keuls test was used for post hoc pair wise comparison whenever the one-way ANOVA revealed statistically significant differences among the groups. Correlations among quantitative variables were tested non-parametrically using the Spearman rank correlation. A two-sided p-value $<0.05$ was considered statistically significant.

\section{ReSUlts}

In this study, $63 \%$ were males, $64 \%$ had hypertension, $71 \%$ had diabetes, $57 \%$ were smokers, $42 \%$ had positive family history for coronary artery disease, $56 \%$ had dyslipidemia and $72 \%$ presented with STEMI.

\subsection{Clinical Findings of the Patients}

\section{- Quantitative Variables}

In the study population, mean $\mathrm{pH}$ was $(7.40 \pm 0.04)$, mean serum bicarbonate level was $(22.9 \pm 2.0)$ $\mathrm{mmol} / \mathrm{l}$, mean base excess was $(-1.9 \pm 2.1) \mathrm{mmol} / \mathrm{l}$, mean anion gap was $(11.0 \pm 5.5) \mathrm{mmol} / \mathrm{l}$, mean serum chloride/sodium ratio was $(0.80 \pm 0.10)$, mean serum uric acid level was $(4.22 \pm 1.24) \mathrm{mg} / \mathrm{dl}$, and mean ejection fraction was $(50.8 \pm 7.9) \%$.

\section{- Categorical Variables}

Among the whole study population, 9 patients $(9 \%)$ had $\mathrm{pH}<7.35,30$ patients $(30 \%)$ had serum bicarbonate level $<22 \mathrm{mmol} / \mathrm{l}, 26$ patients $(26 \%)$ had base excess $>-3 \mathrm{mmol} / \mathrm{l}, 32$ patients $(32 \%)$ had anion gap $>12 \mathrm{mmol} / \mathrm{l}, 52$ patients $(52 \%)$ had chloride/sodium ratio $<0.79,22$ patients $(22 \%)$ had uric acid level $>5 \mathrm{mg} / \mathrm{dl}$, all patients had normal glomerular filtration rate, 25 patients $(25 \%)$ had $\mathrm{EF} \leq$ $45 \%$, while arrhythmia occurred in 17 patients (17\%) and all were ventricular arrhythmias.

\section{- Relation between coronary artery risk factors for and arrhythmia:}

In the study population, risk factors such as smoking, hypertension, diabetes and family history for coronary artery disease are predictors for the occurrence of arrhythmia, while, dyslipidemia, age and male gender are non-predictors.

Table1. Characteristics of the whole study population: Categorical variables

\begin{tabular}{|c|c|c|c|}
\hline Variable & & Number & Percent \\
\hline \multirow[t]{2}{*}{$\mathrm{pH}$} & $\mathrm{pH} \geq 7.35$ & 9 & 9.0 \\
\hline & $\mathrm{pH}<7.35$ & 91 & 91.0 \\
\hline \multirow[t]{2}{*}{ Serum bicarbonate } & Serum $\mathrm{HCO}^{-} \geq 22 \mathrm{mmol} / \mathrm{l}$ & 30 & 30.0 \\
\hline & Serum $\mathrm{HCO}^{-}<22 \mathrm{mmol} / \mathrm{l}$ & 70 & 70.0 \\
\hline \multirow[t]{2}{*}{ Base deficit } & Base deficit $\leq-3 \mathrm{mmol} / \mathrm{l}$ & 74 & 74.0 \\
\hline & Base deficit $>-3 \mathrm{mmol} / \mathrm{l}$ & 26 & 26.0 \\
\hline \multirow[t]{2}{*}{ Anion gap } & Anion gap $\leq 12 \mathrm{mmol} / 1$ & 68 & 68.0 \\
\hline & Anion gap $>12 \mathrm{mmol} / \mathrm{l}$ & 32 & 32.0 \\
\hline \multirow[t]{2}{*}{ Serum chloride/sodium ratio } & Serum $\mathrm{Cl}^{-} / \mathrm{Na}^{+}$ratio $<0.79$ & 52 & 52.0 \\
\hline & Serum SerumCl$/ / \mathrm{Na}^{+}$ratio $\geq 0.79$ & 48 & 48.0 \\
\hline \multirow[t]{3}{*}{ Serum uric acid } & Serum uric acid $\leq 3 \mathrm{mg} / \mathrm{dl}$ & 18 & 18.0 \\
\hline & Serum uric acid $3.1-5$ mgldl & 60 & 60.0 \\
\hline & Serum uric acid $>5 \mathrm{mg} / \mathrm{dl}$ & 22 & 22.0 \\
\hline Glomerular filtration rate & Normal GFR & 100 & 100.0 \\
\hline \multirow[t]{4}{*}{ Ejection fraction } & $\mathrm{EF} \leq 40 \%$ & 14 & 14.0 \\
\hline & $\mathrm{EF} 41 \%-45 \%$ & 11 & 11.0 \\
\hline & EF $46 \%-50 \%$ & 29 & 29.0 \\
\hline & $\mathrm{EF}>50 \%$ & 46 & 46.0 \\
\hline \multirow[t]{2}{*}{ Ejection fraction $\leq 45 \%$} & $\mathrm{EF}>45 \%$ & 75 & 75.0 \\
\hline & $\mathrm{EF} \leq 45 \%$ & 25 & 25.0 \\
\hline \multirow[t]{2}{*}{ Incidence of arrhythmia } & No arrhythmia & 83 & 83.0 \\
\hline & Arrhythmia & 17 & 17.0 \\
\hline \multirow[t]{5}{*}{ Incidence of specific arrhythmias } & Nil & 83 & 83.0 \\
\hline & Premature ventricular contractions & 4 & 4.0 \\
\hline & Ventricular bigeminy & 4 & 4.0 \\
\hline & Ventricular tachycardia & 5 & 5.0 \\
\hline & Ventricular fibrillation & 4 & 4.0 \\
\hline
\end{tabular}


Abdel Mohsen Mostafa Abou Alia et al.

Table2. Relation between coronary artery risk factors and the incidence of arrhythmia

\begin{tabular}{|l|l|l|l|}
\hline Variable & No arrhythmia $(\mathbf{n}=\mathbf{8 3})$ & Arrhythmia $(\mathbf{n}=17)$ & p-value \\
\hline Smoking & $51(61.4 \%)$ & $6(35.3 \%)$ & $0.047 \Phi$ \\
\hline Hypertension & $59(71.1 \%)$ & $5(29.4 \%)$ & $0.001 \Phi$ \\
\hline Diabetes mellitus & $54(65.1 \%)$ & $17(100.0 \%)$ & $0.002 \S$ \\
\hline Dyslipidemia & $46(55.4 \%)$ & $10(58.8 \%)$ & $0.797 \Phi$ \\
\hline Family history of CAD & $42(50.6 \%)$ & $0(0.0 \%)$ & $<0.001 \Phi$ \\
\hline Male gender & $54(65.1 \%)$ & $9(52.9 \%)$ & $0.346 \Phi$ \\
\hline Age $>40$ years & $74(89.2 \%)$ & $17(100.0 \%)$ & $0.351 \S$ \\
\hline NSTEMI & $21(25.3 \%)$ & $7(41.2 \%)$ & $0.236 \S$ \\
\hline EF $\leq 45 \%$ & $13(15.7 \%)$ & $12(70.7 \%)$ & $<0.001 \S$ \\
\hline
\end{tabular}

Data are presented as number (\%).

IIPearson chi-squared test.

$\S$ Fisher's exact test.

\section{- Comparison of Relevant Quantitative Variables in Patients with or Without Arrhythmia}

In this study, arrhythmia occurred in 17 patients (17\%), while there was no arrhythmia in 83 patients $(83 \%)$, mean $\mathrm{pH}$ was $(7.38 \pm 0.06)$ in patients in patients with arrhythmia and $(7.41 \pm 0.04)$ in patients without arrhythmia with $\mathrm{p}=0.055$, mean serum bicarbonate level was $(20.7 \pm 2.2) \mathrm{mmol} / 1$ in patients with arrhythmia and $(23.4 \pm 1.6) \mathrm{mmol} / \mathrm{l}$ in patients without arrhythmia with $\mathrm{p}<0.001$, mean base excess was $(-2.8 \pm 2.6) \mathrm{mmol} / \mathrm{l}$ in patients with arrhythmia and $(-1.8 \pm 1.9) \mathrm{mmol} / \mathrm{l}$ in patients without arrhythmia with $\mathrm{p}=0.053$, mean anion gap was $(14.4 \pm 4.9) \mathrm{mmol} / \mathrm{l}$ in patients with arrhythmia and $(10.2 \pm 5.4) \mathrm{mmol} / 1$ in patients without arrhythmia with $\mathrm{p}=0.004$, mean serum chloride/sodium ratio was $(0.72 \pm 0.02)$ in patients with arrhythmia and $(0.78 \pm 0.05)$ in patients without arrhythmia with $\mathrm{p}<0.001$, mean serum uric acid level was $(5.7 \pm 1.2) \mathrm{mg} / \mathrm{dl}$ in patients with arrhythmia and (3.9 \pm 1.0$)$ in patients without arrhythmia with $\mathrm{p}<0.001$, and mean EF was $(41.9 \pm 4.6) \%$ in patients with arrhythmia and $(52.6 \pm 7.2) \%$ in patients without arrhythmia with $\mathrm{p}<0.001$. there was highly statistically significant differences between patients with and without arrhythmia as regard serum bicarbonate level, reduced serum chloride/sodium ratio, serum uric acid level, and ejection fraction, while there was no statistically significant difference between the two groups of patients as regard $\mathrm{pH}$ level and base excess.

Table3. Comparison of relevant quantitative variables in patients with or without arrhythmia

\begin{tabular}{|l|l|l|l|l|}
\hline Variable & No arrhythmia $(\mathbf{n = 8 3})$ & Arrhythmia $(\mathbf{n = 1 7})$ & $\mathbf{t}$ & p-value $\mathbb{~}$ \\
\hline $\mathrm{pH}$ & $7.41(0.04)$ & $7.38(0.06)$ & 2.051 & 0.055 \\
\hline Serum bicarbonate, $\mathrm{mmol} / \mathrm{l}$ & $23.4(1.6)$ & $20.7(2.2)$ & 4.853 & $<0.001$ \\
\hline Base excess, mmol/l & $-1.8(1.9)$ & $-2.8(2.6)$ & 1.962 & 0.053 \\
\hline Anion gap, mmol/l & $10.2(5.4)$ & $14.4(4.9)$ & -2.962 & 0.004 \\
\hline Serum chloride/sodium ratio & $0.78(0.05)$ & $0.72(0.02)$ & 7.734 & $<0.001$ \\
\hline Serum uric acid, mg/dl & $3.9(1.0)$ & $5.7(1.2)$ & -6.148 & $<0.001$ \\
\hline Ejection fraction, \% & $52.6(7.2)$ & $41.9(4.6)$ & 5.909 & $<0.001$ \\
\hline
\end{tabular}

Data are presented as mean (SD)., IIUnpaired t test.

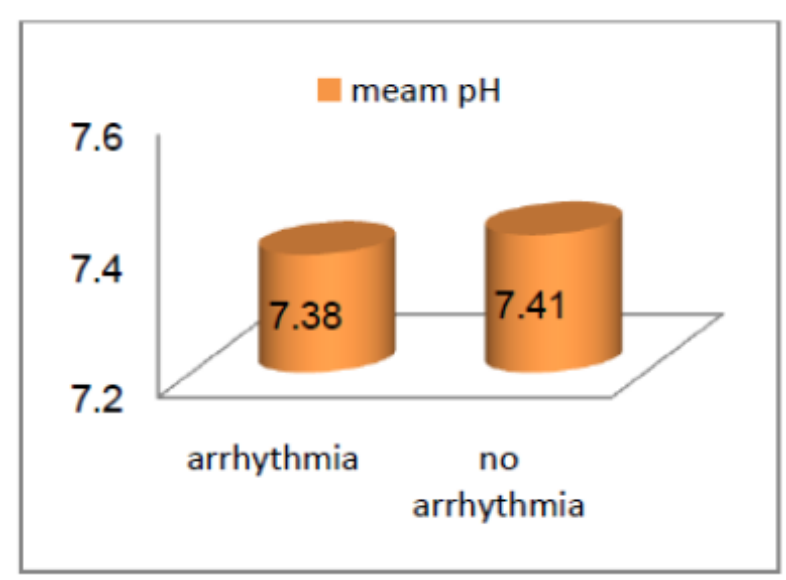

Figure1. mean $\mathrm{pH}$ in patients with and without arrhythmia 


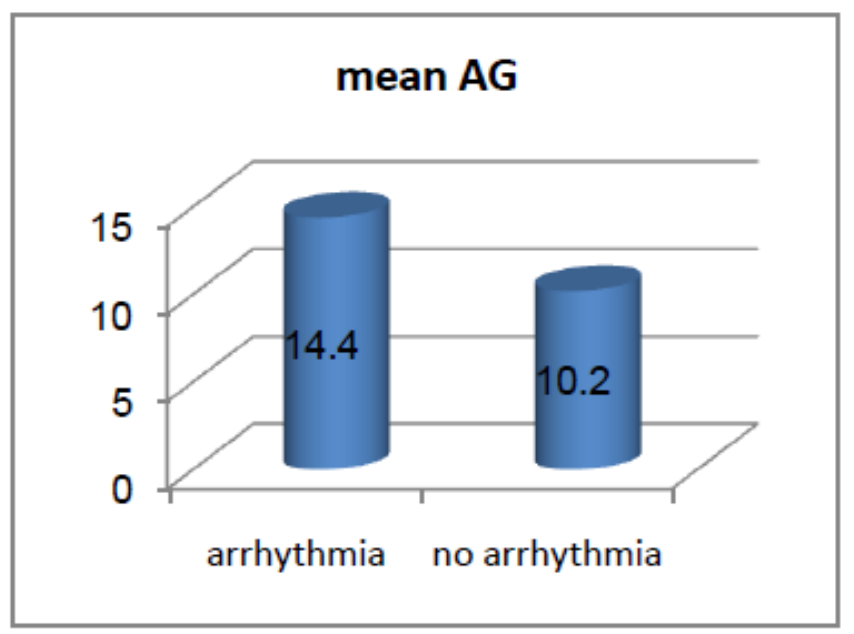

Figure2. mean AG in patients with and without arrhythmia

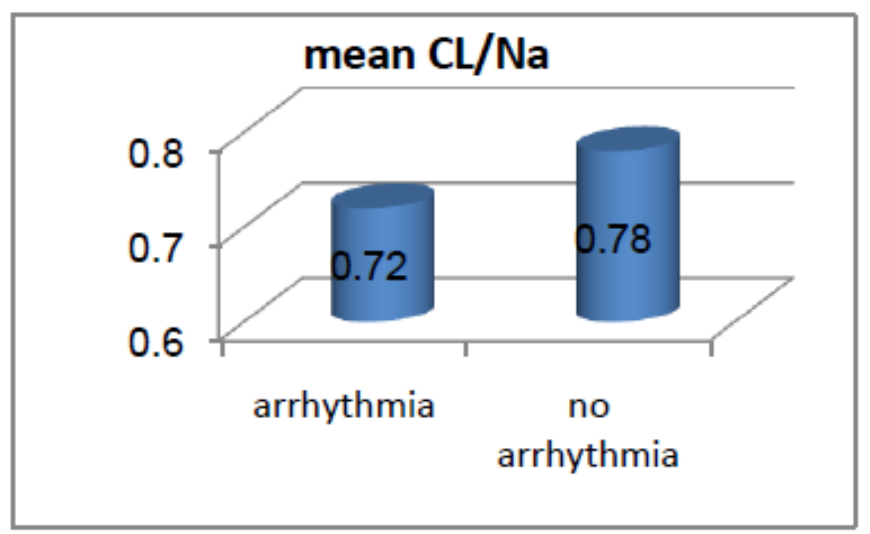

Figure3. mean $\mathrm{Cl}-/ \mathrm{Na}+$ in patients with and without arrhythmia

\section{- Comparison of relevant categorical variables in patients with or without arrhythmia:}

In this study, $\mathrm{pH}<7.35$ was found in $(35.3 \%)$ of patients with arrhythmia and in $(3.6 \%)$ of patients without arrhythmia, serum bicarbonate $<22 \mathrm{mmol} / \mathrm{l}$ was found in $(70.6 \%)$ of patients wiyh arrhythmia and in $(21.7 \%)$ of patients without arrhythmia, base deficit $>3 \mathrm{mmol} / \mathrm{l}$ was found in $(64.7 \%)$ of patients with arrhythmia and in (18.1\%) of patients without arrhythmia, anion gap $>12 \mathrm{mmol} / \mathrm{l}$ was found in $(52.9 \%)$ of patients with arrhythmia and in (27.7\%) of patients without arrhythmia, serum chloride/sodium ratio $<0.79$ was found in all patients with arrhythmia and in $(42.2 \%)$ of patients without arrhythmia, serum uric acid level $>5 \mathrm{mg} / \mathrm{dl}$ was found in $(58.8 \%)$ of patients with arrhythmia and in (14.5\%) of patients without arrhythmia, and EF $\leq 45 \%$ was found in (70.6\%) of patients with arrhythmia and in $(15.7 \%)$ of patients without arrhythmia. There was highly statistically significant differences between patients with and without arrhythmia as regard $\mathrm{pH}<7.35$, serum bicarbonate level $<22 \mathrm{mmol} / \mathrm{l}$, base deficit $>3 \mathrm{mmol} / \mathrm{l}$, serum chloride/sodium ratio $<0.79$, serum uric acid level $>5$ $\mathrm{mg} / \mathrm{dl}$, and $\mathrm{EF} \leq 45 \%$. And there was statistically significant difference as regard $\mathrm{AG}>12 \mathrm{mmol} / \mathrm{l}$.

Table4. Comparison of relevant categorical variables in patients with or without arrhythmia

\begin{tabular}{|l|l|l|l|}
\hline Variable & No arrhythmia $(\mathbf{n}=83)$ & Arrhythmia $(\mathbf{n}=17)$ & p-value \\
\hline $\mathrm{pH}<7.35$ & $3(3.6 \%)$ & $6(35.3 \%)$ & 0.001 II \\
\hline Serum $\mathrm{HCO} 3<22 \mathrm{mmol} / \mathrm{l}$ & $18(21.7 \%)$ & $12(70.6 \%)$ & $<0.001 \S$ \\
\hline Base deficit $>3 \mathrm{mmol} / \mathrm{l}$ & $15(18.1 \%)$ & $11(64.7 \%)$ & $<0.0011 \mathrm{I}$ \\
\hline Anion $\mathrm{gap}>12 \mathrm{mmol} / \mathrm{l}$ & $23(27.7 \%)$ & $9(52.9 \%)$ & $0.042 \S$ \\
\hline Serum $\mathrm{Cl} / \mathrm{Na}^{+}$ratio $<0.79$ & $35(42.2 \%)$ & $17(100.0 \%)$ & $<0.001 \S$ \\
\hline Serum uric acid & & & \\
\hline Serum uric acid $\leq 3 \mathrm{mg} / \mathrm{dl}$ & $18(21.7 \%)$ & $0(0.0 \%)$ & $<0.001 ¥$ \\
\hline Serum uric acid 3.1 $-5 \mathrm{mgldl}$ & $53(63.9 \%)$ & $7(41.2 \%)$ & \\
\hline Serum uric acid $>5 \mathrm{mg} / \mathrm{dl}$ & $12(14.5 \%)$ & $10(58.8 \%)$ & \\
\hline Abnormal GFR & $0(0.0 \%)$ & $0(0.0 \%)$ & - \\
\hline
\end{tabular}


Abdel Mohsen Mostafa Abou Alia et al.

\begin{tabular}{|l|l|l|l|}
\hline \hline Ejection fraction & & & \\
\hline EF $\leq 40 \%$ & $7(8.4 \%)$ & $7(41.2 \%)$ & $<0.001 ¥$ \\
\hline EF $41 \%-45 \%$ & $6(7.2 \%)$ & $5(29.4 \%)$ & \\
\hline EF $46 \%-50 \%$ & $24(28.9 \%)$ & $5(29.4 \%)$ & \\
\hline EF $>50 \%$ & $46(55.4 \%)$ & $0(0.0 \%)$ & \\
\hline Ejection fraction $\leq 45 \%$ & $13(15.7 \%)$ & $12(70.6 \%)$ & 0.001 I \\
\hline
\end{tabular}

Data are presented as number (\%)., ๆFisher's exact test., §Pearson chi-squared test.

$¥ C h$-squared test for linear-by-linear association.

- Relation between coronary artery risk factors and the occurrence of depressed EF $(\leq 45 \%)$ :

In this study, risk factors such as hypertension, dyslipidemia, male gender and family history for coronary artery disease are predictors for the occurrence of reduced EF, while risk factors such as smoking, diabetes and age are non-predictors.

Table5. Relation between various risk factors and the occurrence of depressed ejection fraction $(\leq 45 \%)$

\begin{tabular}{|c|c|c|c|}
\hline Variable & Ejection fraction $>45 \%(n=75)$ & Ejection fraction $\leq 45 \%(n=25)$ & p-value \\
\hline Smoking & $45(60.0 \%)$ & $12(48.0 \%)$ & $0.294 \pi$ \\
\hline Hypertension & $54(72.0 \%)$ & $10(40.0 \%)$ & $0.004 \rrbracket$ \\
\hline Diabetes mellitus & $50(66.7 \%)$ & $21(84.0 \%)$ & $0.098 \rrbracket$ \\
\hline Dyslipidemia & $36(48.0 \%)$ & $20(80.0 \%)$ & $0.005 \pi$ \\
\hline Family history of CAD & $42(56.0 \%)$ & $0(0.0 \%)$ & $<0.001 \Phi$ \\
\hline Male gender & $53(70.7 \%)$ & $10(40.0 \%)$ & $0.006 \mathbb{I}$ \\
\hline Age $>40$ years & $68(90.7 \%)$ & $23(92.0 \%)$ & $1.000 \S$ \\
\hline NSTEMI & $19(25.3 \%)$ & $9(36.0 \%)$ & $0.304 \pi$ \\
\hline Arrhythmia & $5(6.7 \%)$ & $12(48.0 \%)$ & $<0.001 \S$ \\
\hline
\end{tabular}

Data are presented as number (\%)., IPearson chi-squared test., §Fisher's exact test.

- Comparison of Relevant Quantitative Variables among Patients with Various Ranges of Ejection Fraction:

In this study, there was statistically significant difference as regard $\mathrm{pH}$ level between the group of patients with $\mathrm{EF} \leq 40 \%$ and the other groups of patients with various ranges of $\mathrm{EF}$. There was high statistically difference as regard serum bicarbonate level between patients with $\mathrm{EF} \leq 40 \%$ and other groups of patients with various ranges of EF, while there was high statistically difference between the two groups of patients with EF[(41-45\%) and (46-50\%)] and the third group of patients with EF $(>50 \%)$. There was statistically difference as regard base excess between the group of patients with $\mathrm{EF}(46-50 \%)$ and the group of patients with $\mathrm{EF}(>50 \%)$. There was high statistically difference as regard anion gap, serum chloride/sodium ratio, and serum uric acid level between the group of patients with $\mathrm{EF}(\leq 40 \%)$ and patients with $\mathrm{EF}[(46-50 \%)$ and $(>50 \%)]$, while there was high statistically difference between the two groups of patients with $\mathrm{EF}[(41-45 \%)$ and $(46-50 \%)]$ and patients with $\mathrm{EF}(>50 \%)$.

Table6. Comparison of relevant quantitative variables among patients with various ranges of ejection fraction

\begin{tabular}{|l|l|l|l|l|l|}
\hline Variable & $\begin{array}{l}\mathbf{E F} \leq \mathbf{4 0 \%} \\
(\mathbf{n = 1 4})\end{array}$ & $\begin{array}{l}\text { EF 41\% -45\% } \\
(\mathbf{n = 1 1})\end{array}$ & $\begin{array}{l}\mathbf{E F ~ 4 6 \% - 5 0 \%} \\
(\mathbf{n = 2 9})\end{array}$ & $\begin{array}{l}\mathbf{E F}>\mathbf{5 0 \%} \\
(\mathbf{n = 4 6})\end{array}$ & P-valueIl \\
\hline $\mathrm{pH}$ & $7.36(0.06)^{*}$ & $7.41(0.05)$ & $7.41(0.04)$ & $7.41(0.04)$ & 0.002 \\
\hline Serum bicarbonate, $\mathrm{mmol} / \mathrm{l}$ & $20.6(2.2)^{*}$ & $22.5(1.7) \dagger$ & $22.7(1.6) \dagger$ & $23.9(1.40)$ & $<0.001$ \\
\hline Base excess, mmol/l & $-1.8(2.8)$ & $-2.5(1.8)$ & $-2.9(1.7) \dagger$ & $-1.3(2.0)$ & 0.007 \\
\hline Anion gap, mmol/l & $16.0(4.6) \dagger$ & $14.5(4.8) \dagger$ & $12.5(5.6) \dagger$ & $7.6(3.5)$ & $<0.001$ \\
\hline Serum chloride/sodium ratio & $0.72(0.02) \dagger$ & $0.73(0.02) \dagger$ & $0.75(0.04) \dagger$ & $0.81(0.03)$ & $<0.001$ \\
\hline Serum uric acid, $\mathrm{mg} / \mathrm{dl}$ & $5.7(1.1) \dagger$ & $4.8(1.4) \dagger$ & $4.2(1.1) \dagger$ & $3.6(0.8)$ & $<0.001$ \\
\hline
\end{tabular}

Data are presented as mean (SD)., IIOne-way analysis of variance (ANOVA).

*p-value $<0.05$ vs. EF $41 \%-45 \%$, EF 46\%-50\%, and EF >50\% groups (Student-Newman-Keuls test).

$t p$-value $<0.05$ vs. EF $>50 \%$ groups (Student-Newman-Keuls test).

$\$ p$-value $<0.05$ vs. EF 46\%-50\% and EF >50\% groups (Student-Newman-Keuls test).

- Comparison of Relevant Categorical Variables among Patients with Various Ranges of Ejection Fraction;

In this study, there was high statistically difference between all groups of patients with various ranges of ejection fraction as regard $\mathrm{pH}<7.35$, serum bicarbonate level $<22 \mathrm{mmol} / \mathrm{l}$, anion gap $>12$ 
Role of Acid-Base Balance at Admission in Risk Stratification of Patients with Acute Myocardial Infarction

$\mathrm{mmol} / \mathrm{l}$, serum chloride/sodium ratio $<0.79$, serum uric acid level, and incidence of arrhythmia. And there was statistically significant difference between these groups as regard base excess $>-3 \mathrm{mmol} / \mathrm{l}$.

Table7. Comparison of relevant categorical variables among patients with various ranges of ejection fraction

\begin{tabular}{|c|c|c|c|c|c|}
\hline Variable & $\begin{array}{l}E F \leq 40 \% \\
(n=14)\end{array}$ & $\begin{array}{l}\text { EF 41\%-45\% } \\
(n=11)\end{array}$ & $\begin{array}{l}\text { EF 46\%- } \\
50 \%(n=29)\end{array}$ & $\begin{array}{l}\mathbf{E F}>50 \% \\
(\mathrm{n}=\mathbf{4 6})\end{array}$ & P-value \\
\hline $\mathrm{pH}<7.35$ & $7(50.0 \%)$ & $1(9.1 \%)$ & $0(0.0 \%)$ & $1(2.2 \%)$ & $<0.001 \Phi$ \\
\hline Serum $\mathrm{HCO}^{-}<22 \mathrm{mmol} / \mathrm{l}$ & $10(71.4 \%)$ & $4(36.4 \%)$ & $9(31.0 \%)$ & $7(15.2 \%)$ & $<0.001 \Phi$ \\
\hline Base deficit $>-3 \mathrm{mmol} / \mathrm{l}$ & $5(35.7 \%)$ & $5(45.5 \%)$ & $11(37.9 \%)$ & $5(10.9 \%)$ & $0.011 \mathrm{~d}$ \\
\hline Anion gap >12 mmol/l & $11(78.6 \%)$ & $7(63.6 \%)$ & $11(37.9 \%)$ & $3(6.5 \%)$ & $<0.001 \Phi$ \\
\hline Serum $\mathrm{Cl}^{-} / \mathrm{Na}^{+}$ratio $<0.79$ & $14(100.0 \%)$ & $11(100.0 \%)$ & $24(82.8 \%)$ & $3(6.5 \%)$ & $<0.001 \mathrm{dI}$ \\
\hline \multicolumn{6}{|l|}{ Serum uric acid } \\
\hline Serum uric acid $\leq 3 \mathrm{mg} / \mathrm{dl}$ & $0(0.0 \%)$ & $2(18.2 \%)$ & $4(13.8 \%)$ & $12(26.1 \%)$ & $<0.001 \Phi$ \\
\hline Serum uric acid $3.1-5 \mathrm{mg} / \mathrm{dl}$ & $6(42.9 \%)$ & $4(36.4 \%)$ & $18(62.1 \%)$ & $32(69.6 \%)$ & \\
\hline Serum uric acid $>5 \mathrm{mg} / \mathrm{dl}$ & $8(57.1 \%)$ & $5(45.5 \%)$ & $7(24.1 \%)$ & $2(4.3 \%)$ & \\
\hline Abnormal GFR & $0(0.0 \%)$ & $0(0.0 \%)$ & $0(0.0 \%)$ & $0(0.0 \%)$ & - \\
\hline Incidence of arrhythmia & $7(50.0 \%)$ & $5(45.5 \%)$ & $5(17.2 \%)$ & $0(0.0 \%)$ & $<0.001 \Phi$ \\
\hline \multicolumn{6}{|l|}{$\begin{array}{l}\text { Incidence of specific } \\
\text { arrhythmias }\end{array}$} \\
\hline Nil & $7(50.0 \%)$ & $6(54.5 \%)$ & $24(82.8 \%)$ & $46(100.0 \%)$ & $<0.001 \mathbb{I}$ \\
\hline PVCs & $0(0.0 \%)$ & $1(9.1 \%)$ & $3(10.3 \%)$ & $0(0.0 \%)$ & \\
\hline $\mathrm{V}$ bigeminy & $2(14.3 \%)$ & $1(9.1 \%)$ & $1(3.4 \%)$ & $0(0.0 \%)$ & \\
\hline VT & $3(21.4 \%)$ & $1(9.1 \%)$ & $1(3.4 \%)$ & $0(0.0 \%)$ & \\
\hline $\mathrm{VF}$ & $2(14.3 \%)$ & $2(18.2 \%)$ & $0(0.0 \%)$ & $0(0.0 \%)$ & \\
\hline
\end{tabular}

Data are preaented as number (\%)., IIChi-squared test for linear-by-linear association.

\section{- Correlation between EF and Relevant Quantitative Variables:}

In this study, there was a positive correlation between ejection fraction and $\mathrm{pH}$, serum bicarbonate level, base excess, and serum chloride/sodium ratio, but the strongest positive correlation was with serum chloride/sodium ratio. And there was a negative correlation between ejection fraction and anion gap and serum uric acid level.

Table8. Correlation between the ejection fraction and relevant quantitative variables

\begin{tabular}{|l|l|l|}
\hline & & Ejection fraction, \% \\
\hline $\mathrm{pH}$ & Correlation coefficient $(\mathrm{r})$ & 0.315 \\
\hline & p-value & $0.001 \mathrm{I}$ \\
\hline Serum bicarbonate, $\mathrm{mmol} / \mathrm{l}$ & Correlation coefficient $(\mathrm{r})$ & 0.545 \\
\hline & p-value & $<0.0001 \mathbb{I}$ \\
\hline Base excess, mmol/l & Correlation coefficient $(\mathrm{r})$ & 0.208 \\
\hline & p-value & $0.038 \mathrm{I}$ \\
\hline Anion gap, mmol/l & Correlation coefficient $(\mathrm{r})$ & -0.592 \\
\hline & p-value & $<0.0001 \mathbb{I}$ \\
\hline Serum chloride/sodium ratio & Correlation coefficient $(\mathrm{r})$ & 0.799 \\
\hline & p-value & $<0.0001 \mathbb{I}$ \\
\hline Serum uric acid, $\mathrm{mg} / \mathrm{dl}$ & Correlation coefficient $(\mathrm{r})$ & -0.531 \\
\hline & p-value & $<0.0001 \mathbb{I}$ \\
\hline
\end{tabular}

IIPearson product-moment correlation.

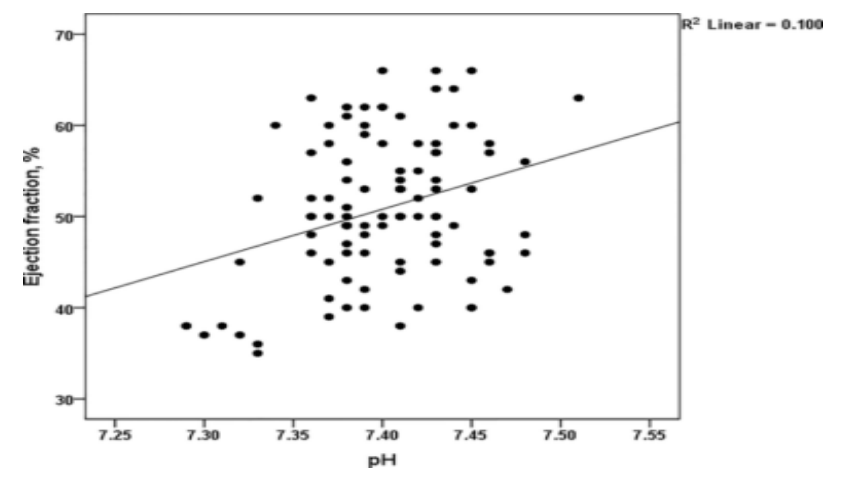

Figure4. Scatter plot showing the correlation between $\mathrm{pH}$ and ejection fraction. 


\section{DISCUSSION}

Little information is available on the acid-base disturbances in the early phase of myocardial infarction. In 1964, MacKenzie et al. observed that patients with cardiogenic shock complicating AMI showed significant metabolic acidosis and a poor prognosis. Neaversonin 1966 documented that significant base deficit occurs in approximately $66 \%$ of AMI.

The acid-base balance provides clinical information, useful for in-hospital risk stratification even in uncomplicated AMI patients (Sahu et al., 2006).

The current study was carried out on (100) patients with the diagnosis of AMI).

Lazzeri et al., 2010 studied acid-base imbalance in 257 consecutive uncomplicated STEMI patients to determine whether its evaluation could help in identifying patients at higher risk for in-hospital complications (acute pulmonary edema and dysrhythmias). Out of these patients, 194 patients $(75.5 \%)$ were males and 63 patients $(24.5 \%)$ were females. Diabetes was present in 46 patients $(17.9 \%)$, hypertension in 127 (49.4\%), while 159 patients $(61.9 \%)$ were smokers. While other risk factors of coronary artery disease were not observed in this study.

In the current study, in the group of patients who developed arrhythmia as a complication, $52.9 \%$ were males, $35.3 \%$ were smokers, $29.4 \%$ had hypertension, $100 \%$ had diabetes, $58.8 \%$ had dyslipidemia, no one had positive family history of coronary artery disease, $41.2 \%$ presented with NSTEMI, and $70.7 \%$ had $\mathrm{EF} \leq 45 \%$.

Among patients who presented with $\mathrm{EF} \leq 45 \%, 40 \%$ were males, $48 \%$ were smokers, $40 \%$ had hypertension, $84 \%$ had diabetes, $80 \%$ had dyslipidemia, no one had positive family history of coronary artery disease, $36 \%$ presented with NSTEMI, and $48 \%$ had arrhythmia.

In the current study, characteristics of the whole study population revealed that acidemia (that is $\mathrm{pH}<7.35)$ was present in 9 patients $(9 \%) . \mathrm{HCO}_{3}<22$ was present in 30 patients $(30 \%)$. Base deficit $>$ 3 was present in 26 patients $(26 \%)$. AG $>12$ was present in 32 patients $(32 \%)$. serum $\mathrm{Cl}^{-} / \mathrm{Na}^{+}<0.79$ was present in 52 patients $(52 \%)$. While serum uric acid level $>5 \mathrm{mg} / \mathrm{dl}$ was present in 22 patients $(22 \%)$.

In Lazzeri et al., 2010, acidemia was present in 11 patients (4.2\%). Where as in the overall population; $\mathrm{HCO}_{3}(<22)$ was present in 62 patients $(24.1 \%)$. Base excess $>-3$ was detected in 70 patients (27.2\%). Anion gap > 12 was detected in 13 patients $(5.1 \%)$. While a $\mathrm{Cl}^{-} / \mathrm{Na}^{+}<0.79$ was present in 93 patients (38.5\%). Among patients with $\mathrm{AG} \leq 12$, one-third $(33 \%)$ exhibited a $\mathrm{Cl}^{-} / \mathrm{Na}^{+}<$ 0.79 , which was detected in all patients with $\mathrm{AG}>12$.

In this study, comparison of relevant categorical variables in patients with or without arrhythmia revealed that $\mathrm{pH}<7.35$ was found in 3 out of 83 patients without arrhythmia (3.6\%), while it was found in 6 out of 17 patients with arrhythmia $(35.3 \%)$ with p-value $(<0.001)$. Serum bicarbonate level $<22 \mathrm{mmol} / \mathrm{l}$ was found in 18 out of 83 patients without arrhythmia $(21.7 \%)$, while it was found in 12 out of 17 patients with arrhythmia $(70.6 \%)$ with p-value $(<0.001)$. Base deficit $>3 \mathrm{mmol} / \mathrm{l}$ was found in 15 out of 83 patients without arrhythmia (18.1\%), while it was found in 11 out of 17 patients with arrhythmia $(64.7 \%)$ with p-value $(<0.001)$. Anion gap $>12 \mathrm{mmol} / \mathrm{l}$ was found in 23 out of 83 patients without arrhythmia (27.7\%), while it was found in 9 out of 17 patients with arrhythmia $(52.9 \%)$ with p-value (0.042). Serum chloride/sodium ratio < 0.79 was found in 35 out of 83 patients without arrhythmia (42.2\%), while it was found in all patients with arrhythmia $(100 \%)$ with p-value $(<0.001)$. Serum uric acid level ( in $\mathrm{mg} / \mathrm{dl}$ ) in patients without arrhythmia was $\leq 3$ in 18 out of 83 patients (21.7\%), and 3.1-5 in 53 out of 83 patients $(63.9 \%)$, and > 5 in 12 out of 83 patients (14.5\%); while in patients with arrhythmia, it was 3.1-5 in 7 out of 17 patients (41.2\%), and > 5 in 10 out of 17 patients $(58.8 \%)$ with p-value $(<0.001)$. Ejection fraction $\leq 45 \%$ was found in 13 out of 83 patients without arrhythmia (15.7\%), while it was found in 12 out of 17 patients with arrhythmia (70.6\%) with p-value $(<0.001)$.

Toshiyuki et al., 2010 studied the effect of systemic acidosis on the development of malignant ventricular arrhythmias, including sustained ventricular tachycardia and ventricular fibrillation (VT/VF), after reperfused ST-elevation myocardial infarction (STEMI). A total of 157 consecutive patients with a reperfused STEMI were examined. Patients were divided into 2 groups according to the presence or absence of systemic acidosis, defined as arterial blood $\mathrm{pH}<7.40$ on admission. 
Systemic acidosis was observed in 53 patients (34\%), including 36 patients with metabolic, 8 with respiratory, and 9 with mixed acidosis. There was no significant difference in age, sex, coronary risk factors, preinfarction angina, and incidence of hypoxia ( $\mathrm{PaO} 2<80$ Torr) on admission between patients with and without acidosis. Estimated glomerular filtration rate (eGFR) on admission was lower in patients with acidosis than those without $(\mathrm{p}=0.019)$. Patients with acidosis had a higher incidence of VT/VF ( $26 \%$ vs. $4 \%, \mathrm{p}<0.0001$ ), especially within 48 hours after STEMI (23\% vs. 3\%, $\mathrm{p}=0.0002)$, than those without. In-hospital cardiac mortality $(\mathrm{p}=0.36)$ was not significantly different between patients with and without acidosis. As a conclusion to this study, patients with acidosis had a higher incidence of VT/VF (26\% vs. $4 \%, \mathrm{P}<0.0001)$, especially within $48 \mathrm{~h}$ after STEMI (23\% vs. $3 \%, \mathrm{P}=0.0002)$, than those without. Multivariate analysis showed that systemic acidosis was a strong independent predictor of $\mathrm{VT} / \mathrm{VF}$ (relative risk $=8.79, \mathrm{P}=0.002$ ) among variables including prior $\mathrm{MI}$.

There is agreement in the results of this study and the results of Toshiyuki et al. as both of them proved that acidosis increases the risk of ventricular arrhythmias after AMI. The difference is that this study included patients with STEMI and NSTEMI, while Toshiyuki et al. included patients with STEMI only.

In this study, comparison of relevant categorical variables among patients with various ranges of ejection fraction revealed that $\mathrm{pH}<7.35$ was found in (50\%) of patients with $\mathrm{EF} \leq 40 \%,(9.1 \%)$ of patients with EF $41-45 \%$, and $(2.2 \%)$ of patients with $\mathrm{EF}>50 \%$; p-value $(<0.001)$. Serum bicarbonate $<22$ was found in $(71.4 \%)$ of patients with $\mathrm{EF} \leq 40 \%$, (36.4\%) of patients with $\mathrm{EF} 41-45 \%,(31 \%)$ of patients with EF 46-50\%, and (15.2\%) of patients with EF $>50 \%$; p-value $(<0.001)$. Base deficit $>-3$ was found in (35.7\%) of patients with $\mathrm{EF} \leq 40 \%$, (45.5\%) of patients with $\mathrm{EF} 41-45 \%$, (37.9\%) of patients with $\mathrm{EF} 46-50 \%$, and $(10.9 \%)$ of patients with $\mathrm{EF}>50 \%$; p-value $(<0.011)$. Anion gap $>12$ was found in (78.6\%) of patients with $\mathrm{EF} \leq 40 \%,(63.6 \%)$ in patients with $\mathrm{EF} 41-45 \%$, $(37.9 \%)$ of patients with EF 46-50\%, and (6.5\%) of patients with $\mathrm{EF}>50 \%$; p-value $(<0.001)$. Serum $\mathrm{Cl}^{-} / \mathrm{Na}^{+}$ ratio $<0.79$ was found in $(100 \%)$ of patients with $\mathrm{EF} \leq 40 \%$, (100\%) of patients with $\mathrm{EF} 41-45 \%$, $(82.8 \%)$ of patients with EF $46-50 \%$, and $(6.5 \%)$ of patients with EF $>50 \%$; p-value $(<0.001)$. Serum uric acid level $>5$ was found in $(57.1 \%)$ of patients with $\mathrm{EF} \leq 40 \%$, (45.5\%) of patients with $\mathrm{EF} 41$ $45 \%,(24.1 \%)$ of patients with $\mathrm{EF} 46-50 \%$, and $(4.3 \%)$ of patients with $\mathrm{EF}>50 \%$; p-value $(<0.001)$. Incidence of arrhythmia was (50\%) of patients with $\mathrm{EF} \leq 40 \%$, (45.5\%) of patients with $\mathrm{EF} 41-45 \%$, (17.2\%) of patients with $\mathrm{EF} 46-50 \%$, and no arrhythmia was found in patients with $\mathrm{EF}>50 \%$; $\mathrm{p}$-value $(<0.001)$.

In Lazzeri et al., 2010 patients with AG > 12 exhibited a lower LVEF ( $\mathrm{P}=0.037)$, incidence of intracoronary care unit global complications was $23.1 \%(\mathrm{P}=0.560)$, while mean uric acid level in this group was $5.0 \mathrm{mg} / \mathrm{dl}(\mathrm{p}=0.641)$. Patients with $\mathrm{Cl}-\mathrm{Na}^{+}<0.79$ had a lower LVEF $(\mathrm{P}=0.042)$, higher latency $(\mathrm{P}=0.029)$, that is the time from symptom onset to revascularization, and a higher incidence of intra-ICCU global complications $(\mathrm{P}=0.017)$, while mean uric acid level in this group was 5.3 $(\mathrm{p}=0.252)$.

There is agreement in the results of this study and that of Lazzeri et al. as regard the anion gap and $\mathrm{Cl}^{-}$ $/ \mathrm{Na}^{+}$ratio, but Lazzeri et al. did not include other variables of acid-base imbalance.

The dominant mechanism for the reduction of contractility with acidosis is competitive inhibition of the slow calcium current by hydrogen ions. The slow calcium current initiates cardiac contraction and contributes to the action potential. The major effect of acidosis on the action potential of ventricular muscle is to cause a lengthening owing to inhibition of potassium exchange and as a consequence of reduced calcium current. The reduced contractility is dependent upon the severity of the acidosis (Kimmoun et al., 2012).

Another clinical trial reported that when isolated cardiac muscle, whole heart, muscle strip, or single cell is exposed to acidosis, the force of contraction decreases. This decrease is faster in response to interventions that rapidly alter intracellular, rather than extracellular $\mathrm{pH}$, indicating that intracellular acidosis is responsible for the decrease (Vaughan-Jones et al. 1987). During prolonged exposure to acidosis a secondary recovery of developed force can also be observed (Orchard, 1987).

The amplitude of the intracellular systolic $\mathrm{Ca}^{2+}$ transient, which initiates contraction, has been reported, variously, to increase, decrease, or not change, during the initial decrease of developed force. The time course of the transient is prolonged (Orchard, 1987).Thus, it appears that the decrease 
in developed force is not due to a decrease of activating $\mathrm{Ca}^{2+}$, and it is now generally accepted that the negative inotropic effect of acidosis is due predominantly to a decrease in the sensitivity of the contractile proteins to $\mathrm{Ca}^{2+}$ (Orchard and Kentish 1990). The secondary recovery of developed force that occurs during acidosis is, however, accompanied by (i) an increase in diastolic $\mathrm{Ca}^{2+}$, (ii) an increase in the amplitude of the systolic $\mathrm{Ca}^{2+}$ transient, which appears to underlie the contractile recovery and (iii) recovery of the time course of the $\mathrm{Ca}^{2+}$ transient (DeSantiago et al., 2004).

In the current study, there was positive correlation between ejection fraction and $\mathrm{pH}$, serum bicarbonate level, base excess, and serum chloride/sodium ratio. While there was negative correlation between ejection fraction and anion gap, and between ejection fraction and serum uric acid level.

No previous clinical trials studied this correlation.

\section{Conclusions}

- Smoking, hypertension, diabetes and family history for coronary artery disease are predictors for the occurrence of arrhythmia, while, dyslipidemia, age and male gender are non-predictors.

- Hypertension, dyslipidemia, male gender and family history for coronary artery disease are predictors for the occurrence of reduced EF, while risk factors such as smoking, diabetes and age are non-predictors.

- $\mathrm{PH}$, serum bicarbonate level, base excess, serum chloride/sodium ratio and anion gap are indicators for the occurrence of arrhythmia and reduced ejection fraction.

\section{RECOMMENDATIONS}

From the finding of this study we can recommend that:

- Control of risk factors for coronary artery disease.

- Early detection of even minor degrees of acidosis and trying to treat it, as this may reduce early complications of acute myocardial infarction.

- The basic metabolic profile done as a part of the routine laboratory assessment of all patients with AMI.

- Future studies should include correction of acidosis if present and assessment of the role of this correction on the incidence of early complications of AMI, particularly arrhythmias and reduced EF.

\section{REFERENCES}

Cascio W, Johnson $\mathbf{T}$ and Gettes $\mathbf{L}$.: Electrophysiologic changes in ischemic ventricular myocardium: I. Influence of ionic, metabolic and energic changes. J Cardiovasc Electrophysiol 1995; 11: 1039 - 1062.

Cheng H, Smith GL, Orchard CH, et al.: Acidosis inhibits spontaneous activity and membrane currents in myocytes isolated from the rabbit atrioventricular node. J Mol Cell Cardiol 2009;46;75-85.

DeSantiago J, Maier LS and Bers DM.: Phospholamban is required for CaMKII-dependent recovery of Ca transients and SR Ca reuptake during acidosis in cardiac myocytes. J Mol Cell Cardiol 2004; 36, 67-74.

Durward A, Skellett S, Mayer A, et al.: The value of the chloride: sodium ratio in differentiating the aetiology of metabolic acidosis. Intensive Care Med 2001; 27:828-835.

Kapur S, Wasserstorm JA, Kelly JE, et al.: Acidosis and ischemia increase cellular Ca2+ transient alternans and repolarization alternans susceptibility in the intact rat heart. Am J Physiol Heart Circ Physiol 2009; 296;H1491-H1512.

Kimmoun A, Ducrocq $\mathbf{N}$ and Levy B.: New conclusive data on human myocardial dysfunction induced by acidosis. Crit Care 2012; 28;16(5):160.

Lang RM, Bierig M, Devereux RB, et al.: Chamber Quantification Writing Group, American Society of Echocardiography's Guidelines and Standards Committee, European Association of Echocardiography, Recommendations for chamber quantification: a report from the American Society of Echocardiography's Guidelines and Standards Committee and the Chamber Quantification Writing Group, developed in conjunction with the European Association of Echocardiography, a branch of the European Society of Cardiology. J Am Soc Echocardiogr 2005; 18(12):1440-1463. 
Lazzeri C, Valente S, Chiostri M, et al.: Acid-base imbalance in uncomplicated acute myocardial infarction: the role of tissue acidosis. Intern Emerg Med 2010; 5:61-66.

Levey AS, Stevens LA, Schmid CH, et al.: Chronic Kidney Disease Epidemiology Collaboration (CKD-EPI): a new equation to estimate glomerular filtration rate. Ann Intern Med 2009;150:604-612.

MacKenzie GJ, Taylor SH, Flenley DC, et al.: Circulatory and respiratory studies in myocardial infarction and cardiogenic shock. Lancet 1964;2:825-832.

Morris CG and Low J.: Metabolic acidosis in the critically ill: part 1: classification and pathophysiology. Anaesthesia 2008;63:294-301.

Neaverson MA.: etabolic acidosis in acute myocardial infarction. Br Med J 1966; 2:383-385.

Orchard CH and Cingolani HE.: Acidosis and arrhythmia in cardiac muscle. Cardiovasc Res 1994; 28;1312-1319.

Orchard CH and Kentish JC.: Effects of changes of PH on the Contractile function of cardiac muscle. Am J Physiol 1990;258;C967-C981.

Orchard CH.: The role of the sarcoplasmic reticulum in the response of ferret and rat heart muscle to acidosis. J Physiol 1987;384, 431-449.

Sahu A, Cooper HA and Panza JA.: The initial anion gap is a predictor of mortality in acute myocardial infarction. Coron artery dis 2006;17;409-412.

Schotola H, Toischer K, Popov AF, et al.: Mild metabolic acidosis impairs the $\beta$-adrenergic response in isolated human failing myocardium. Crit Care 2012; 16(4):R153.

Thygesen K, Alpert JS, Jaffe AS, et al.: Joint ESC/ACCF/AHA/WHF Task Force for the Universal Definition of Myocardial Infarction. Third universal definition of myocardial infarction. Circulation 2012;126(16):2020-2035.

Toshiyuki N, Anzai T, Kaneko H, et al.: Impact of systemic acidosis on the development of malignant ventricular arrhythmias after reperfusion therapy for ST-elevation myocardial infarction. Circ J 2010;74(9):1808-1814.

Valente S, Lazzeri C, Chiostri M, et al.: NT-proBNP on admission for early risk stratification in STEMI patients submitted to PCI. Relation with extension of STEMI and inflammatory markers. Int J Cardiol 2009;132;84-89. Veronique R, Go AS, Lloyd-Jones et al.: Heart disease and stroke statistics-2011 update: a report from the American heart association statistics committee and stroke statistics subcommittee. Circulation, 2011,123:e18-e209.

Vaughan-Jones RD, Eisner DA and Lederer WJ.: Effects of changes of intracellular pH on contraction in sheep cardiac Purkinje-fibres. J Gen. Physiol 1987;89, 1015-1032. 